\title{
A política de financiamento da educação no estado de Rondônia entre 2007 e $2019^{1}$
}

Education funding policy in the brazilian state of Rondônia from 2007 to 2019 La política de financiamiento de la educación en el estado de Rondônia entre 2007 y 2019

\author{
ALESSANDRA BERTASI NASCIMENTO \\ https://orcid.org/0000-0002-7894-1180 \\ Universidade Federal de Mato Grosso do Sul \\ Programa de Pós-graduação em Educação \\ Departamento de Educação \\ Nova Andradina, MS, Brasil \\ MARIA DILNÉIA ESPÍNDOLA FERNANDES \\ https://orcid.org/0000-0001-5218-8541 \\ Universidade Estadual de Campinas \\ Programa de Pós-Graduação em Educação \\ Departamento de Educação \\ Campo Grande, MS, Brasil \\ LEANDRO SAUER \\ https://orcid.org/0000-0003-4882-428X \\ Universidade Federal de Mato Grosso do Sul \\ Programa de Pós-Graduação em Administração \\ Escola de Administração e Negócios \\ Campo Grande, MS, Brasil
}

\begin{abstract}
Resumo: $\mathrm{O}$ texto analisa, em contexto federativo, a política de financiamento da educação no estado de Rondônia, de 2007 a 2019. Trabalhou-se com a legislação educacional, com os relatórios resumidos da execução orçamentária, documentos da imprensa e do movimento sindical docente. Constatou-se que a política de financiamento da educação no estado se desenvolveu em dois ciclos no período, porque foi subordinada à política econômica. $\mathrm{O}$ primeiro ciclo foi marcado pela ampliação do direito à educação. O segundo ciclo moveu-se pela austeridade fiscal, rompendo o ciclo imediatamente anterior.
\end{abstract}

Palavras-chave: Política educacional. Financiamento para MDE. Fundeb no estado de Rondônia. Austeridade Fiscal.

1 Realizado com o apoio da Coordenação de Aperfeiçoamento de Pessoal de Nível Superior - Brasil (Capes) - Código de Financiamento 001, do Conselho Nacional de Desenvolvimento Científico e Tecnológico (CNPq) e da Universidade Federal de Mato Grosso do Sul- UFMS/MEC - Brasil. 
Abstract: The text analyzes, the education funding policy in the Brazilian state of Rondônia in a federative context from 2007 to 2019. The research included the education legislation, the budget execution summary reports, press documents, and documents written by the teaching union movement. The education funding policy in the state was developed in two cycles in the period as it was subordinated to economic policy. The first cycle was marked by the expansion of the right to education. The second cycle was moved by fiscal austerity, by breaking the immediately previous cycle.

Key words: Education policy. Funding for MDE. Fundeb in the state of Rondônia. Fiscal Austerity.

Resumen: El texto analiza, en el contexto federativo, la politica de financiamiento de la educación en el estado de Rondônia, de 2007 a 2019. Se trabajó con la legislación educacional, con los informes resumidos de la ejecución presupuestaria, documentos de la prensa y del movimiento sindical docente. Se constató que la política de financiamiento de la educación en el estado se desenvolvió en dos ciclos en el periodo, porque fue subordinada a la política económica. El primer ciclo fue marcado por la ampliación del derecho a la educación. El segundo ciclo se movió por la austeridad fiscal, rompiendo el ciclo inmediatamente anterior.

Palavras-chave: Politica educacional. Financiamiento para MDE. Fundeb em el estado de Rondônia. Austeridad Fiscal.

\section{INTRODUÇÃO}

A aprovação da Emenda Constitucional n. 95 (BRASIL, 2016), que instituiu o Novo Regime Fiscal e congelou por 20 anos, nos patamares de 2017, os gastos federais primários públicos para a área social, ocorreu na conjuntura político-econômica pós "golpe legislativo-judicial-midiático" (AMARAL, 2017, p. 5). Tal fato significou, sobretudo, a desvinculação de recursos financeiros, para colocar em vigência a agenda ultraliberal em contexto de austeridade fiscal, com sérias alterações no padrão de financiamento da política social, tendo como imperativo a redução das ações do Estado para a área.

O ciclo de políticas educacionais herdadas do momento anterior, mas ainda em curso, passou a ser norteado pelo contexto de austeridade fiscal. Com isso, alteraram-se as políticas educacionais construídas para ampliar o direito à educação, cuja concepção se expressou na aprovação da Lei n. 13.005 (BRASIL, 2014), que instituiu o Plano Nacional de Educação (PNE 2014-2024) e alinhou o planejamento educacional em contexto federativo. O PNE 2014-2024, para a materialização de suas metas e consequentes estratégias, dispôs-se a gastar, até o final do decênio, 10\% do Produto Interno Bruto (PIB). Tal dispositivo sucumbiu diante da austeridade fiscal (AMARAL, 2017).

O gasto de 10\% do PIB em educação, em contexto federativo, exigiria de cada ente seu quinhão de esforço, dado que "[...] a variação da receita de impostos pode ser muito diferente - para mais e para menos - entre as unidades federadas 
de acordo com a riqueza produzida por cada uma." (ARELARO; FERNANDES, 2015). Isso porque o financiamento para Manutenção e Desenvolvimento do Ensino (MDE), dispositivo constitucional, advém da receita de impostos da União em interseção com os diversos entes federativos, ainda que a receita de cada um deles seja originada das suas expensas e se transforme em despesa mediante o binômio centralização versus descentralização.

O ciclo das políticas educacionais a partir do século XX teve, no PNE 2014-2024, sua expressão de condensação como epicentro da política educacional (DOURADO, 2017). Sua importância se dá porque a

[...] discussão sobre políticas e gestão da educação [...], expressa uma tessitura sócio-política complexa, que se articula às agendas transnacionais, ao Estado nacional, a relação entre os entes federados, às especificidades do Sistema educacional brasileiro, à gestão, à avaliação e ao financiamento, à qualidade e às concepções político-pedagógicas norteadoras, entre outros. (DOURADO, 2017, p. 176).

Remonta ao período a principal política de financiamento da educação básica, originada na vinculação constitucional de recursos para MDE, que criou uma subvinculação, instituída pela Emenda Constitucional n. 53, regulamentada pela Lei n. 11.494 e pelo Decreto Presidencial n. 6.253, que instituiu o Fundo de Manutenção e Desenvolvimento da Educação Básica e de Valorização dos Profissionais da Educação - Fundeb - (BRASIL, 2006, 2007b, 2007a), cuja vigência seria até 2020. Apesar da disputa de diferentes forças sociais no país, foi aprovado no Senado Federal e se tornou permanente. Foi promulgado como Emenda Constitucional n. 108 (BRASIL, 2020).

Os recursos para MDE, que compõem a conta estadual única do Fundeb, têm origem na receita própria de impostos de cada ente federativo. No caso do Fundeb, a subvinculação de $20 \%$ dos impostos estaduais considera as matrículas da educação básica do ano anterior, registradas no censo educacional. Quando dividida a soma total dos impostos pelas matrículas, tem-se o valor do custo aluno ano mínimo (VAA) de cada ente federado. Esse valor do VAA nas esferas subnacionais não pode ser inferior ao VAA nacional, definido anualmente nos termos da legislação do Fundeb. Quando as receitas de impostos de cada ente federativo, em particular, não alcançam o VAA nacional, a União deve complementar os recursos.

O Fundeb, ao substituir o Fundo de Manutenção e Desenvolvimento do Ensino Fundamental e de Valorização do Magistério (Fundef), ampliou o direito à educação, por considerar o conjunto das matrículas da educação básica (CURY, 2014). Também manteve, como o Fundef, o lastro de percentual de recursos do fundo para a remuneração docente, mediante a obrigatoriedade de 
Planos de Cargos, Carreira e Remuneração Docente (PCCRs) em cada unidade federativa. Sobretudo, o Fundeb criou dispositivos para a instituição do Piso Salarial Profissional Nacional (PSPN) em lei específica (BRASIL, 2007a).

A Lei n. 11.738 (BRASIL, 2008), ainda que aprovada fora do prazo instituído pela Lei do Fundeb, entre outros direitos docentes, instituiu o PSPN. A materialidade do PSPN, todavia, transformou-se em contenda federativa (FERNANDES; RODRIGUEZ, 2011). Por meio de uma Ação Direta de Inconstitucionalidade (ADIn), Governadores estaduais alegaram quebra de autonomia federativa por parte da União, quando determinou, em Lei, o pagamento do PSPN na interseção da política educacional. O Fundeb poderia ser uma política de coordenação federativa, no que tange à diminuição de assimetrias regionais, nesse caso, a partir de um patamar mínimo do valor da força de trabalho docente, bem como da instituição da jornada de trabalho docente de 1/3 sem a presença de educandos. Fato foi que a Lei n. 11.738 (BRASIL, 2008) só começou a vigorar em 2013, retroativa a 2011, quando a União ganhou a causa no Supremo Tribunal Federal (FERNANDES; MIURA, 2019).

É nesse contexto federativo, portanto, que este artigo objetiva analisar os possíveis efeitos da Emenda Constitucional n. 95 (BRASIL, 2016) para as receitas e despesas em MDE no estado de Rondônia, no período de 2007 a 2019.

Trabalhou-se com a legislação educacional, Relatórios Resumidos da Execução Orçamentária (RREOs), referentes ao período de janeiro a dezembro/ bimestre novembro-dezembro, publicados no Diário Oficial do Estado (DOE), no primeiro bimestre do ano subsequente. Os valores correntes foram corrigidos para fevereiro de 2020, pelo Índice Nacional de Preço ao Consumidor (INPC), do Instituto Brasileiro de Geografia e Estatística (IBGE), por meio da calculadora do cidadão, disponibilizada pelo Banco Central.

Além da introdução do artigo, na primeira seção apresentam-se os recursos disponíveis para financiar a política educacional do estado de Rondônia, de 2007 a 2019. Na segunda, expõem-se os montantes de gastos em MDE e do Fundeb no estado, cotejados às responsabilidades educacionais no período em tela. Em seguida, tecem-se as considerações finais.

\section{RONDÔNIA: RECURSOS FINANCEIROS PARA A POLÍTICA EDUCACIONAL}

No estado de Rondônia, a educação foi o setor com a maior distribuição de despesa ao longo da série histórica de 2007 a 2019 (gráfico 1). Isso se deveu à obrigatoriedade constitucional de vinculação de percentual mínimo de impostos. 
Embora a educação, em âmbito nacional, já sentia o efeito de cortes desde 2015, decorrentes da política macroeconômica adotada pelo governo federal (ROSSI et al., 2019), em Rondônia a diminuição dos recursos se fez sentir em 2013 e 2014. O estado retomou o crescimento em 2016 e seguiu com resultados inconstantes, sem atingir o patamar de 2013.

A análise dessa despesa, por meio do ajuste da linha de tendência, descontada a influência da inflação, revela a seguinte expressão: (Educação = $\mathrm{R} \$ 18.027 .219,20$ Ano + R\$1.040.817.796,30). Em média, de 2007 a 2019, o aumento nas despesas com educação foi da ordem de $\mathrm{R} \$ 18.027 .219,20$. A linha de tendência, via regressão linear simples, explica significativamente a variabilidade dos dados (ANOVA, $\mathrm{p}=0,02, \mathrm{R} 2^{2}=40,4 \%$ ).

\section{Gráfico 1 - Distribuição das três maiores despesas realizadas pelo governo estadual, por especificação. Rondônia, 2007-2019}

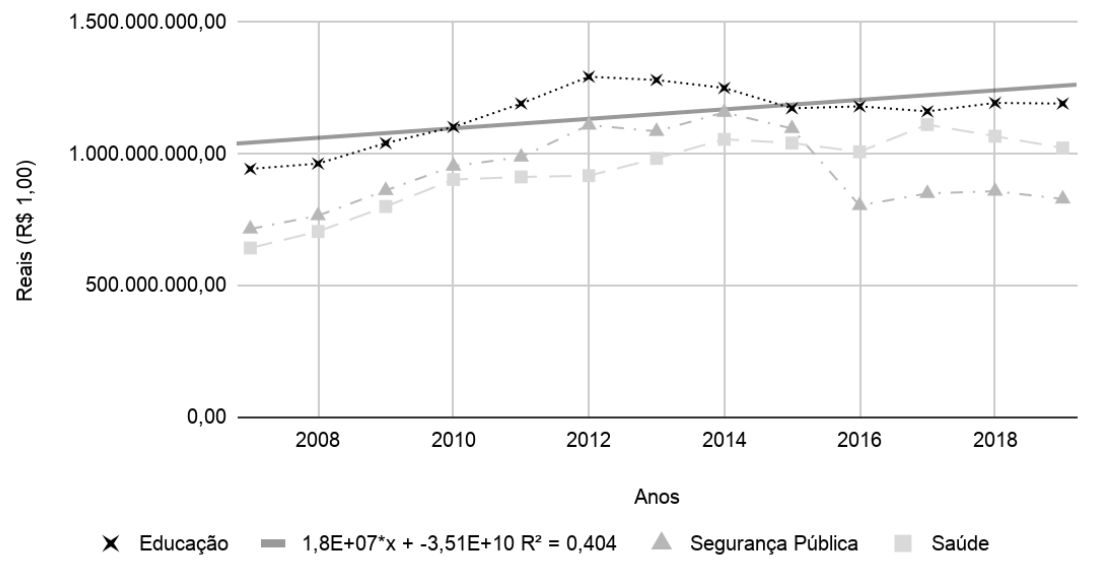

Fonte: Elaborado pela autoria a partir de: RREOs (RONDÔNIA, 2008b, 2009b, 2010, 2011, 2012b, 2013, 2014, 2015c, 2016, 2017, 2018, 2019, 2020).

Contudo, no estudo do comportamento norteado pela conjuntura político-econômica adotada pelos governos federais no período pré e pós impeachment, 2007 a 2016 e 2016 a 2019, respectivamente, obtivemos nuances distintas.

2 "Esta medida mostra o quanto o comportamento das variáveis $\mathrm{X}$ explicam a variação de $\mathrm{Y}$ e não justifica uma relação de causalidade da variável Y pelo vetor de variáveis X. [...] O R2 pode variar entre 0 e 1 (0 a 100\%), porém é praticamente impossível a obtenção de um R2 igual a 1, uma vez que dificilmente todos os pontos cairão em cima de uma reta. Em outras palavras, se o R2 for 1, não haverá resíduos para cada uma das observações da amostra em estudo. Porém, se as variáveis explicativas não forem adequadas para explicar o comportamento de Y, o R2 ficará próximo de 0.” (FÁVERO et al., 2009, p. 353). 
De 2007 a 2016, a linha de tendência representada pela expressão Educação $=\mathrm{R} \$ 32.084 .840,62$ Ano $+\mathrm{R} \$ 995.300 .893,30$ expôs investimento médio da ordem de $\mathrm{R} \$ 32.084 .849,62$. O valor foi maior que o referente ao levantamento de todo o período.

De 2016 a 2019, período de mudanças na política econômica pósimpeachment, no contexto da aprovação da Emenda Constitucional n. 95 (BRASIL, 2016), mas sem franca influência decorrente de sua aprovação, a equação estimada foi: Educação = R \$6.396.541,05 Ano + 1.169.976.674,00; um investimento médio da ordem de $\mathrm{R} \$ 6.396 .541,05$. Esse valor implicou significativa redução média da ordem de $\mathrm{R} \$ 25.688 .308,57$ ao ano, mesmo com divulgação do crescimento de 5,4\% do Produto Interno Bruto (PIB) do estado de Rondônia em 2017, comparado ao ano de 2016 (RONDONOTÍCIAS, 2019).

A análise da série história, em contexto político-econômico diverso de ciclo anterior, reitera a defesa da importância da vinculação mínima de $25 \%$ dos impostos específicos, visando à relativa estabilidade de recursos e possibilidades de investimento na educação, a fim de que não se mantivesse refém de prioridades governamentais (GOUVEIA; SOUZA 2015).

Ainda que setores sociais, em processo de correlação de forças que se materializaram em textos legais, tenham conseguido conquistas relacionadas ao aumento do direito à educação e ao financiamento para que seja pública, laica, de qualidade e socialmente referenciada, os estudos das emendas constitucionais correlatas à educação demonstram que o financiamento da educação para MDE no Brasil foi e continua marcado por histórica recusa da ampliação de recursos por parte do Estado (OLIVEIRA; FERNANDES, 2018).

No gráfico 2, verifica-se que as principais fontes que compõem o Fundeb, a receita do Imposto Sobre Circulação de Mercadorias e Serviços (ICMS) e o Fundo de Participação dos Estados (FPE), tiveram coeficiente angular da linha de tendência, com comportamento ascendente de 134,68 e 44 milhões/ ano e R2 com ajuste da linear de 75\%, 47\% e 67\% para o conjunto de dados, respectivamente.

Também se explicita o crescimento da receita líquida de impostos, ICMS e FPE, ainda que tenha passado por oscilações em 2009, 2012, 2013 e 2015. Esses anos sugeriram subprocessos, decorrentes dos elementos dos anos de crise nacional, com efeito na economia estadual, quais sejam: em 2009, no governo Lula, refletiu-se a crise mundial, com consequente estagnação da exportação (MARCONI; BRANCHER, 2017); em 2012, no primeiro mandato de Dilma, em decorrência da forte contração fiscal e desaceleração do PIB, ainda que se tenha introduzido a retomada de ações expansionistas, com controle de gastos correntes (em ação até 2014), não se obtiveram resultados positivos no crescimento 
(BARBOSA, 2013); 2013, portanto, expressou o efeito no endividamento das famílias, diminuição do consumo, redução na estrutura do mercado de trabalho e renda familiar (BASTOS, 2017), culminando em manifestações populares; e, em 2015, a recessão (DWECK; TEIXEIRA, 2017), com aumento na taxa de desemprego e de arrecadação (MELLO; ROSSI, 2017).

\section{Gráfico 2 - Receita por especificação. Rondônia, 2007-2019 (R\$1,00)}

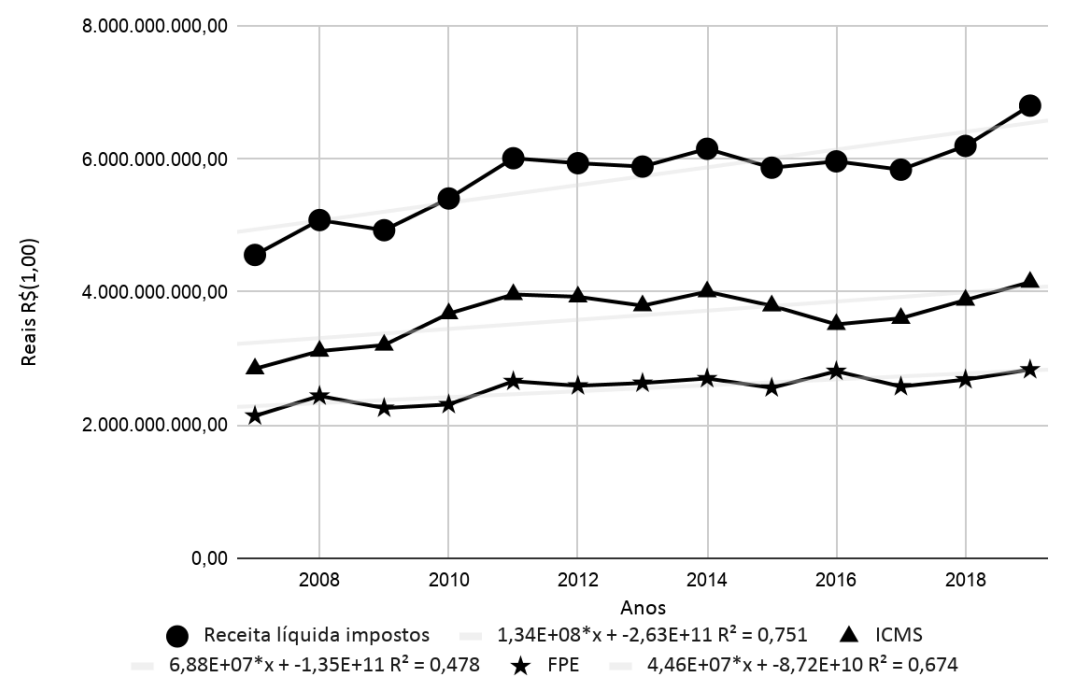

Fonte: Elaborado pela autoria a partir de: RREOs (RONDÔNIA, 2008b, 2009b, 2010, 2011, 2012b, 2013, 2014, 2015c, 2016, 2017, 2018, 2019, 2020).

No Brasil, a variação acumulada no ano do Índice Nacional de Preço ao Consumidor Amplo (IPCA), segundo o IBGE (2019), saltou de 3,14\% (2006) para 5,9\% (2008), 6,41\% (2014), 10,6\% (2015), dando mostras do impacto na renda das famílias brasileiras e, por conseguinte, no consumo. Seguiu em queda para 6,29\% (2016), 2,95\% (2017), aumento para 3,75\% (2018) e 4,31\% (2019) sem, no entanto, superar o percentual de 2008 a 2015.

Considerando que a receita do Fundeb e a base de $25 \%$ de incidência para financiar a MDE, a Despesa de MDE por subfunção e do Fundeb com remuneração de profissionais do magistério são indicadores que auxiliam compreender a evolução das finanças dos fundos, de MDE e valorização docente, itens que serão analisados a seguir. 


\section{MDE E FUNDEB NO ESTADO DE RONDÔNIA}

Para formar o Fundeb, compuseram o gráfico 3 a transferência de contribuição do estado à formação dos fundos, a transferência dos fundos e a receita líquida do Fundeb em Rondônia.

\section{Gráfico 3 - Formação do Fundeb, por especificação. Rondônia, 2007-2019}

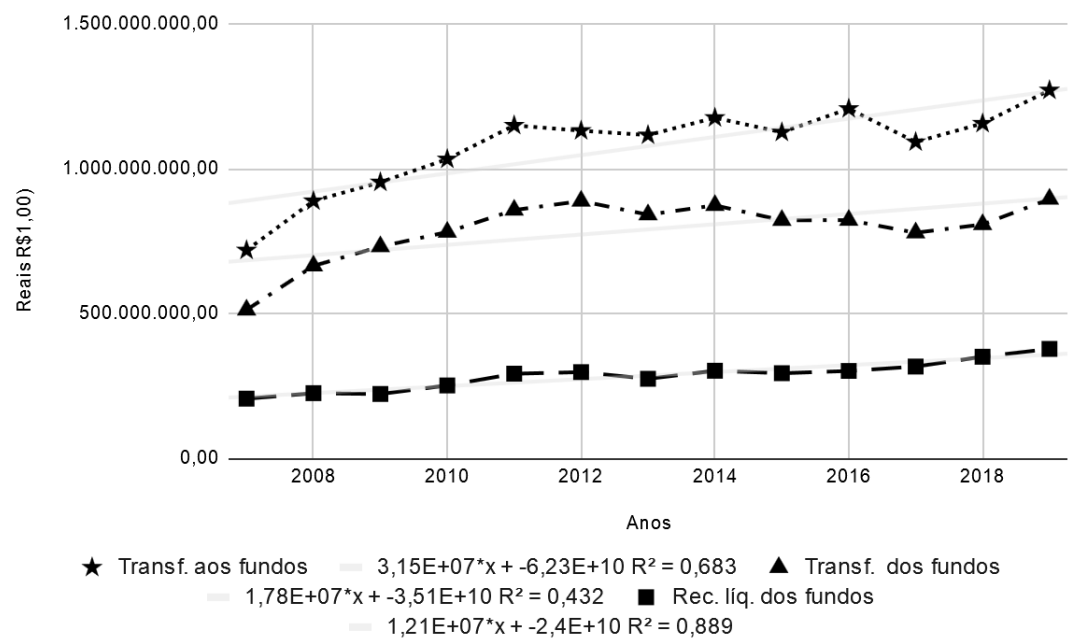

Fonte: Elaborado pela autoria a partir de: RREOs (RONDÔNIA, 2008b, 2009b, 2010, 2011, 2012b, 2013, 2014, 2015c, 2016, 2017, 2018, 2019, 2020).

Nas três séries de dados, respectivamente, o coeficiente angular da linha de tendência teve comportamento ascendente de 31,5, 17,8 e 12,1 milhões/ano e R2 com ajuste da linear de 68\%, 43\% e 88\%.

Em quaisquer anos, Rondônia apresentou decréscimo ao receber as transferências do fundo, contribuindo para a redistribuição a outros entes federados, a fim de corrigir desigualdades. Entretanto, nas publicações dos RREOs, os sinais orientadores de acréscimo $(+)$ ou decréscimo $(-)$ só foram registrados a partir de 2015, aspecto não contributivo à transparência nas prestações de contas neles veiculadas, com omissão frente aos manuais de elaboração dos RREOs (BRASIL; MINISTÉRIO DA FAZENDA; SECRETARIA DO TESOURO NACIONAL, 2007). 
Constatou-se, pelos RREOs, que o estado não recebeu complementação da União às transferências dos fundos, crescente até 2012 e com resultados oscilantes até 2017 , quando voltou a mostrar elevação, com maior transferência de valores à composição da cesta do Fundeb, conforme o valor numérico do resultado líquido.

É da receita líquida de impostos e transferências, após dedução das transferências constitucionais aos municípios, que se compõe a receita de MDE. No caso de Rondônia, em que há decréscimo na receita líquida dos fundos, o percentual de MDE mínimo de $25 \%$ a ser aplicado é calculado pela soma das despesas de ações típicas, receita líquida dos fundos, restos a pagar cancelados e aplicações financeiras, dividido pelo total líquido de impostos e transferências x 100, conforme os manuais de elaboração dos RREOS.

Utilizando-se a fórmula descrita, foram recalculados os dados informados nos RREOS a partir dos valores correntes. Os resultados revelaram comportamento descendente para o percentual de MDE informado (-2,69), com R2 em 0 e para o percentual recalculado $(-0,0549)$, com R2 igual a 0,054 .

\section{Gráfico 4 - Percentual de MDE informado nos RREOS e recalculado. Rondônia, 2007-2019}

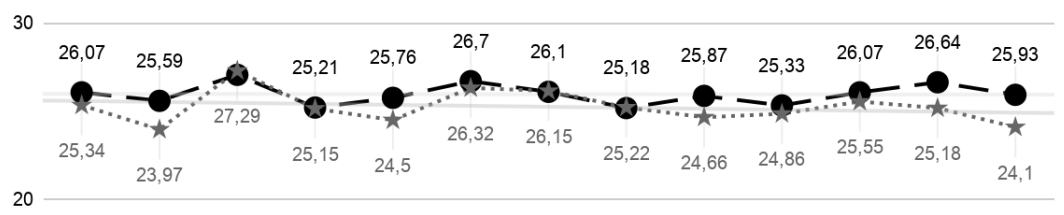

10

\begin{tabular}{|c|c|c|c|c|c|c|c|c|c|c|c|c|}
\hline 2007 & 2008 & 2009 & 2010 & 2011 & 2012 & 2013 & 2014 & 2015 & 2016 & 2017 & 2018 & 2019 \\
\hline
\end{tabular}

Fonte: Elaborado pela autoria a partir de: RREOs (RONDÔNIA, 2008b, 2009b, 2010, 2011, 2012b, 2013, 2014, 2015c, 2016, 2017, 2018, 2019, 2020). 
A comparação dos resultados expressa a não aplicação de $25 \%$ das receitas líquidas de impostos e transferências em MDE nos anos de 2008, 2011, 2015, 2016 e 2019. Esses anos foram diferentes daqueles registrados para a queda da receita líquida $(2009,2013)$, exceto 2015 , momento em que a recessão econômica já estava instalada, e 2019.

A aplicação da receita de MDE, demonstrada no gráfico 5, explicitou que as despesas com o ensino médio e o total das ações típicas tiveram comportamento ascendente, com coeficiente angular da linha de tendência em 33,2 milhões, 32,4 milhões e 16,4 milhões/ano, respectivamente. Entretanto, essa mesma prova, aplicada ao ensino fundamental, revelou comportamento decrescente, -7,96 milhões/ano. O ajuste linear (R2) para a receita e total de despesa foi de $82 \%$ e $43 \%$, respectivamente. Tais resultados não se confirmaram para o ensino fundamental, em 1,3\% e ensino médio, em 14,3\%.

\section{Gráfico 5 - Receita e despesa de MDE, por especificação. Rondônia, 2007-2019}

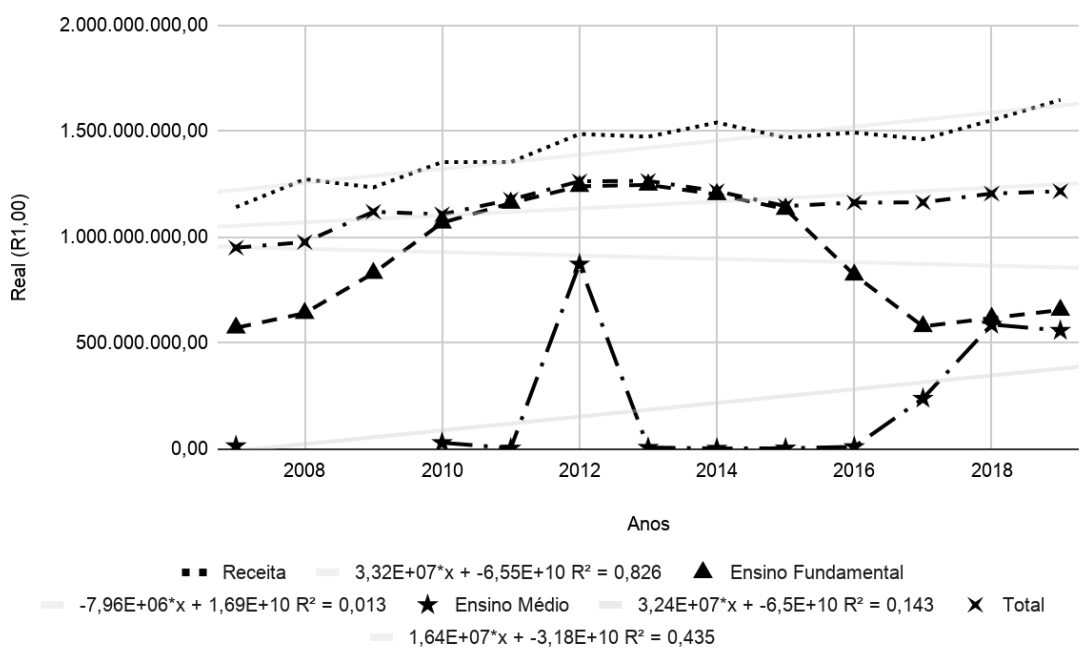

Fonte: Elaborado pela autoria a partir de: RREOs (RONDÔNIA, 2008b, 2009b, 2010, 2011, 2012b, 2013, 2014, 2015c, 2016, 2017, 2018, 2019, 2020).

No caso do ensino fundamental, a partir de 2014, constatou-se decréscimo de matrícula migrada para o âmbito municipal, em virtude da política de reordenamento criada pelo Governo do Estado de Rondônia, por meio do Decreto n. 20.070 (RONDÔNIA, 2015a). O documento instituiu o Programa de Parceria Educacional Estado-Município, para universalizar o atendimento 
do ensino fundamental e firmar um termo de cooperação com os municípios para que se responsabilizassem, gradativamente, pela primeira etapa do ensino fundamental $\left(1^{\circ}\right.$ ao $5^{\circ}$ ano $)$.

Para o ensino Médio, os RREOS dos anos de 2008 e 2009 não registraram dados. Houve, na série, uma grande variação nos valores de investimento. Em 2016, com a política de reordenamento, o investimento aumentou; tornou a expressar redução em 2019.

Os totais de receita e de despesa em MDE não mantiveram o mesmo comportamento na série. A receita cresceu a partir de 2017. A despesa, após redução e variação entre os anos de 2015 a 2018, retomou o valor de 2014 (1,214 bilhão).

No tocante às matrículas, turmas e funções docentes para a série histórica, conforme tabela 1 , o número total de matrículas anual entrou em decréscimo desde 2010, chegando, em 2019, com -26\% que em 2009.

\section{Tabela 1 - Número de matrículas, turmas e funções docentes da educação básica estadual. Rondônia, 2007-2019}

\begin{tabular}{|c|c|c|c|}
\hline Anos & Matrículas & Turmas & Funções docentes \\
\hline 2007 & 257414 & 8658 & 7357 \\
\hline 2008 & 260744 & 8716 & 7651 \\
\hline 2009 & 263738 & 8897 & 7835 \\
\hline 2010 & 255860 & 8937 & 7914 \\
\hline 2011 & 250421 & 8985 & 8282 \\
\hline 2012 & 246731 & 9038 & 8255 \\
\hline 2013 & 240870 & 9045 & 8315 \\
\hline 2014 & 233367 & 8828 & 8014 \\
\hline 2015 & 228467 & 8485 & 7646 \\
\hline 2016 & 217077 & 7830 & 6808 \\
\hline 2017 & 204110 & 7566 & 6597 \\
\hline 2018 & 196530 & 7577 & 6466 \\
\hline 2019 & 195085 & 7442 & 6155 \\
\hline
\end{tabular}

Fonte: Elaborada pela autoria a partir de: Laboratório de dados Educacionais dos microdados do Censo Escolar/INEP (2020).

Já o número de turmas e funções docentes foi crescente até 2013, ano em que começou a vigorar o PSPN. Anotou-se decréscimo, a partir de então, em ambos os indicadores, de modo a atingir em 2019, respectivamente, $-21,5 \%$ e $-26 \%$, em relação a 2013. O percentual de redução de matrículas foi igual à redução de funções docentes na série histórica. 
O gráfico 6 informa os percentuais de aplicação de MDE e do Fundeb em despesa com profissionais do magistério. Os resultados revelaram comportamento ascendente para o percentual aplicado do Fundeb (0,312), com R2 em 1,6\% e comportamento descendente para o percentual de aplicação em MDE de 26,9\%, com R2 igual a zero.

\section{Gráfico 6 - Percentuais de aplicação de MDE e do Fundeb em despesa com profissionais do magistério, rede estadual de educação básica. \\ Rondônia, 2006-2016}

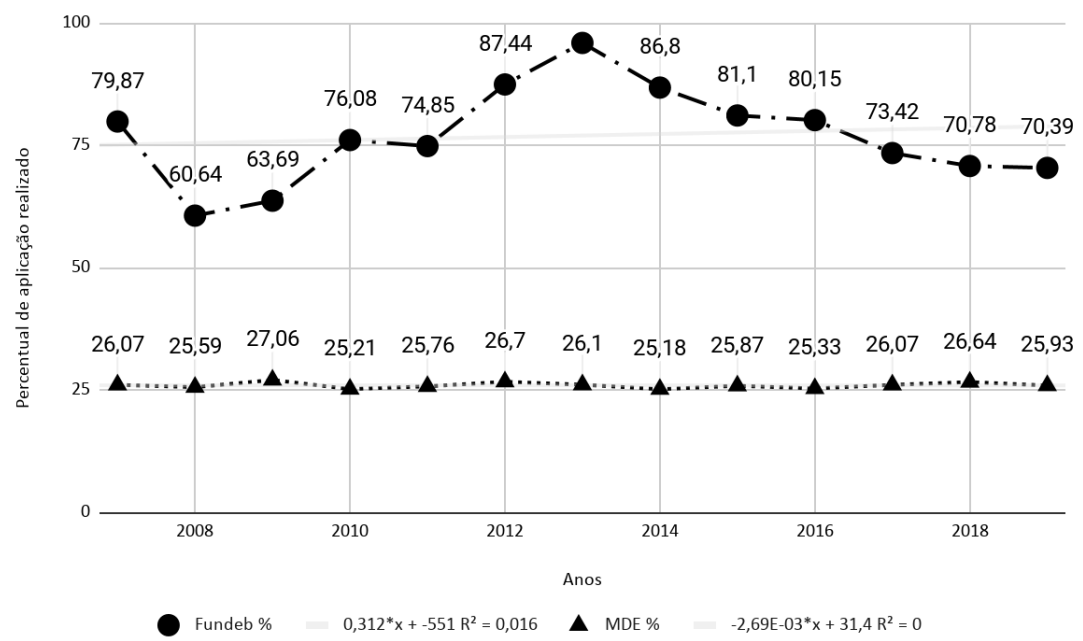

Fonte: Elaborado pela autoria a partir de: RREOs (RONDÔNIA, 2008b, 2009b, 2010, 2011, 2012b, 2013, 2014, 2015c, 2016, 2017, 2018, 2019, 2020).

A partir de 2014, o percentual de aplicação do Fundeb em despesa com profissionais do magistério reduziu, acompanhando a queda no número de matrículas, turmas e funções docentes.

Em 2018 e 2019, o percentual permaneceu em 70\%, uma diferença aproximada de $25 \%$, em comparação com 2013 , seu maior investimento.

Nesse cenário estruturou-se a reivindicação da categoria docente, devido às perdas salariais de aproximadamente $35 \%$ e à proposta recusada de reajuste linear de 6\%, no ano de 2011, indicando a possibilidade de utilização de parte do percentual de 25\% de MDE para investimento em educação (NASCIMENTO, 2019). 
Essa possibilidade é reiterada na informação "[...] as receitas que podem ser destinadas ao pagamento de salários docentes não se restringem às receitas do Fundeb. Elas são mais amplas, porque são as de MDE, como determina a legislação educacional em vigência." (FERNANDES; FERNANDES, 2016).

O gráfico 7 auxilia a aprofundar a análise. Tanto a receita recebida do Fundeb quanto a despesa com os profissionais do magistério tiveram comportamento ascendente na linha de tendência, em 16,8 milhões e 14,5 milhões/ano e R2 42,7\% e 19,7\%, respectivamente.

\section{Gráfico 7 - Receita recebida do Fundeb e despesa com profissionais do magistério. Rondônia, 2007-2019}

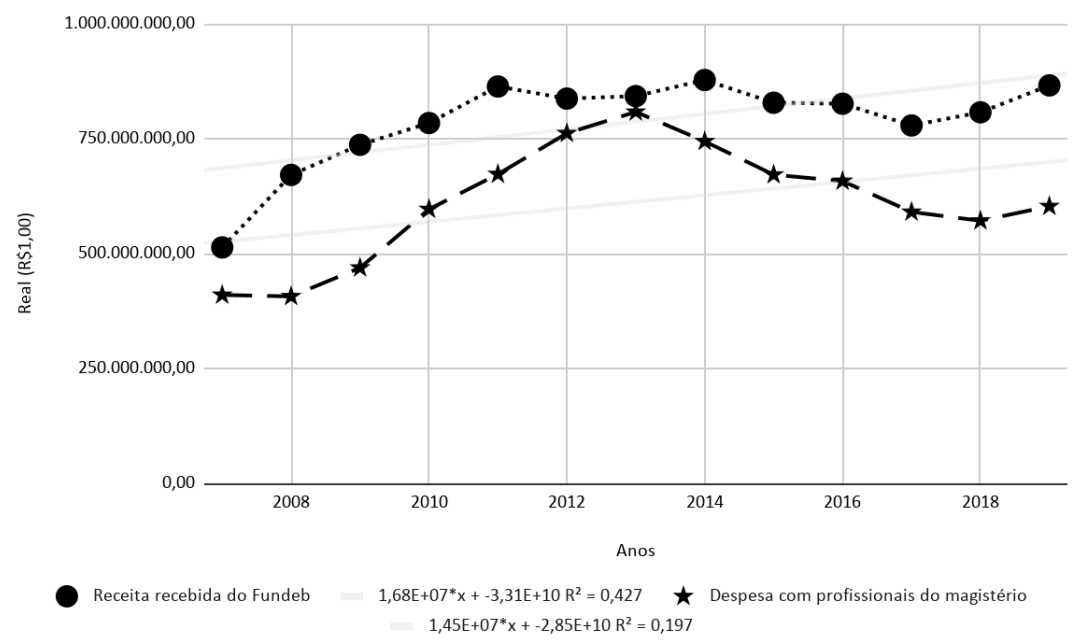

Fonte: Elaborado pela autoria a partir de: RREOs (RONDÔNIA, 2008b, 2009b, 2010, 2011, 2012b, 2013, 2014, 2015c, 2016, 2017, 2018, 2019, 2020).

Existem três períodos básicos a serem levados em conta: o início do Fundeb, a implantação do PSPN e a vigência da Emenda Constitucional n. 95 (BRASIL, 2016).

O ano de 2007 marcou a transição para o Fundeb, com ampliação da cobertura para a educação básica. Em relação ao ano anterior, o número de turmas aumentou $2 \%$. O estado passou a contribuir com a formação da cesta a ser redistribuída e, ainda assim, a transferência do fundo aumentou, o que poderia explicar a redução de $83 \%$ para 79,86\% de aplicação do Fundeb com remuneração dos profissionais do magistério, apesar da queda de $17 \%$ do número de professores em função docente. 
Especificamente em 2007, as funções docentes por formação incluíam 925 com Ensino Médio e 6.390 com Educação Superior. Nesse ano, havia uma mobilização para a reposição salarial aguardada desde 2005, e ainda se esperava a implantação do primeiro Plano Estadual de Educação, o que possibilitaria clara política para a educação. Isso só veio a se efetivar com a aprovação da Lei no 3.565 (RONDÔNIA, 2015b).

Em 2008, houve a continuidade de queda do percentual realizado do Fundeb para remuneração dos profissionais do magistério, 60,63\%. Nesse ano, foi aprovada a Lei Complementar n. 420 (RONDÔNIA, 2008a), o segundo PCCR estadual. O texto inicial dessa Lei resultou do consenso entre os profissionais da educação e representantes do governo. Todavia, efetivou-se a instituição de texto diverso, sem consentimento da categoria profissional interessada, no ano em que foi aprovada a Lei do Piso para a categoria nacional de professores (BRASIL, 2008).

De acordo com a Confederação Nacional dos Trabalhadores em Educação (CNTE, 2008a), a categoria respondeu com greve geral. Entre os itens de pauta para 2008, constavam: a luta por um índice de reajuste salarial no orçamento do estado (CNTE, 2008c), decorrente de política de arroxo salarial durante os dois mandatos do governador Ivo Cassol (2003-2010); adequação dos quadros da Secretaria de Estado da Educação (Seduc) à Lei do Piso (vencimento e jornada de trabalho) (CNTE, 2008b); e enquadramento de professores que haviam concluído a Educação Superior entre 2003 e 2007 ao segundo PCCR (CNTE, 2008c). Todas eram estratégias para obtenção de reajuste salarial.

A despesa do Fundeb com remuneração docente teve resultado crescente de aplicação entre os anos de 2009 e 2013, quando atingiu 95,92\% de aplicação do Fundo.

Destacam-se a redução do número de funções docentes no Ensino Médio, o aumento nas funções com formação em Educação Superior e o aumento do número de turmas. Em 2009, o governo, ainda em política de restrição de reajustes no vencimento, justificou a redução do número de funções docentes pela crise econômica de 2008. Esse argumento foi rebatido pelo Sindicato dos Trabalhadores em Educação de Rondônia (CNTE, 2009).

Ainda em 2009, foi aprovada a Lei Complementar n. 499 (RONDÔNIA, 2009a), segundo a qual os professores "Leigos e com formação em Nível Médio que não alcançarem o PSPN" $\left(\right.$ art. $1^{\circ}$ ) receberiam, segundo o art. $2^{\circ}$, o pagamento de "dois terços da diferença entre a remuneração recebida e o valor do PSPN" como complemento "na remuneração $[\ldots]$ ". 
Em 2012, o art. $2^{\circ}$ da Lei supracitada foi modificado: "será da exata diferença entre a remuneração recebida e o valor vigente no Piso Salarial Nacional do Magistério" (RONDÔNIA, 2012a). A correção conteve despesa para o estado, que seguiu a tendência de outros da federação brasileira a ter o PSPN incidindo no vencimento de professores no início de carreira, mas não na carreira como um todo, de modo que o piso tivesse efeito de teto (GOUVEIA; BASSI, 2016; GOUVEIA; FERRAZ, 2016).

Em 2012 e 2013, o aumento do percentual de utilização do Fundeb pode ser explicado pelo efeito do reajuste de $40 \%$ de algumas gratificações que atingiram os profissionais do magistério, proporcionado pela Lei Complementar n. 662 (RONDÔNIA, 2012a), somado ao impacto da implantação do terceiro PCCR, aprovado pela Lei Complementar n. 680 (RONDÔNIA, 2012b), apesar da queda na receita líquida de impostos e transferências.

O PCCR vigente (RONDÔNIA, 2012b) especifica, no artigo 74:

O valor do vencimento inicial dos profissionais do magistério será determinado a partir do piso salarial profissional nacional estabelecido pela Lei Federal $n^{\circ}$ 11.738, de 16 de julho de 2008, sendo este valor proporcional conforme a jornada de trabalho e classe.

Tal redação estabeleceu texto diverso do constante no $\int 1^{\circ}$ do artigo $2^{\circ}$ da Lei do Piso (BRASIL, 2008), ao fixar um valor mínimo para jornadas de, no máximo, 40 horas semanais e abaixo do qual os entes federados não poderiam consolidar o vencimento inicial das carreiras do magistério público da educação básica.

A contar de 2014, o percentual de aplicação do Fundeb em remuneração dos profissionais do magistério entrou em decréscimo por influência, em princípio, da política de reordenamento, seguido da gradativa diminuição do número de funções docentes, turmas e matrículas, em aprofundamento de contenção de despesas e enxugamento da máquina estatal.

Para a série histórica, a média percentual de aplicação do Fundeb em remuneração dos profissionais do magistério foi de 79,05\%. Tal resultado, em contexto federativo, aproxima Rondônia dos resultados de pesquisas as quais apontaram ampliação desses percentuais acima de 60\% dos fundos (ARELARO, 1999; PINTO, 2007). 


\section{CONSIDERAÇÕES FINAIS}

A análise dos dados para a série histórica no estado de Rondônia demonstrou a existência de dois ciclos na política de financiamento e remuneração docente em contexto federativo. O primeiro conteve dois subprocessos: o início da vigência do Fundeb e a aprovação da Lei do Piso.

Nesse primeiro ciclo, a conquista de direitos em âmbito nacional fixou o Fundeb, a Lei do Piso e o Plano Nacional de Educação. Essa legislação permitiu, por meio da ação sindical, tensionar as pautas de luta que se expressaram no primeiro subprocesso, frente à política de arroxo salarial e à ausência de clara política de educação, com vigência anterior ao Fundeb.

Seguiram-se a luta por adequação dos quadros da Seduc à Lei do Piso e a aprovação do primeiro Plano Estadual de Educação pela Lei no 3.565 (RONDÔNIA, 2015b).

Resulta que, no primeiro ciclo, com a política econômica adotada, a despesa em Educação cresceu. Contudo, o investimento na remuneração docente não expressou valorização, pois o percentual de aplicação do Fundeb com remuneração aumentou conforme a receita e decresceu com o aumento de funções docentes. Nessa relação, também diminuiu o número de docentes com formação em Nível Médio/Normal, onde o PSPN incide, e aumentou o número de docentes com formação em Educação Superior, que tende ao achatamento.

O pós-impeachment marcou o segundo ciclo, quando se retiraram as políticas imediatamente anteriores, com efeito de redução de investimentos na Educação rondoniense, ainda que diante de aumento na receita líquida de impostos e, por consequência, na formação e receita líquida do Fundeb. Todavia, o percentual de investimento do Fundeb com remuneração docente reduziu para a faixa de $70 \%$, inferior ao patamar de 2010 , quando ainda se vivenciava o arroxo salarial decorrente da política do governo de Ivo Cassol.

Diante do cenário recente, que reconfigura as políticas educacionais em contexto de austeridade fiscal, por meio de restrição orçamentária, com vistas a manter a lógica rentista do projeto hegemônico de sociedade, a principal política de financiamento da educação básica encontra-se, também, em disputa, por setores da sociedade brasileira.

A aprovação do PNE 2014-2024, com o alinhamento do planejamento educacional em contexto federativo, preservou políticas anteriores, que guardavam vínculos constitucionais e as ampliou, objetivando reduzir processos de desigualdades de toda ordem, que se expressam na política educacional e que, historicamente, obstaculizam e interrompem oportunidades. 
Em contexto federativo, o caso do estado de Rondônia contribui para demonstrar a influência dos ciclos das políticas econômicas no financiamento da política educacional e de como esta se subordina àquelas. As influências evidenciam-se principalmente no tocante à política educacional, pois os dispositivos da vinculação constitucional de recursos e suas subvinculações estão ordenados pelas políticas de fundos com montantes de financiamento para MDE, cujos valores oscilam diante da economia, porque são percentuais sobre a receita de impostos.

A indução da União, que cria condições jurídico-legais para os entes federativos aderirem às políticas, como é o caso das políticas de fundos e da valorização docente mediante os dispositivos da Lei n. 11.738 (BRASIL, 2008), no caso do estado de Rondônia, demonstrou que os arranjos locais também se revestem de importância para a materialidade da política educacional.

Observou-se que, no caso do estado de Rondônia, porque em contexto federativo, a interseção da política educacional promovida recebeu efeitos das determinações da política econômica. Tal fato constatou-se na receita e despesa para MDE, bem como na condução do pagamento do PSPN, no início e na estrutura da carreira docente.

O caso do estado de Rondônia é, assim, ilustrativo dos ciclos que se processaram no período em tela. Inicialmente, ocorreu um período de interseção da política educacional, com vistas a ampliar o direito à educação, por meio de seu financiamento e da ampliação da reprodução da força de trabalho docente, ainda que tal situação tenha sido afetada pela política econômica. Uma nova situação se evidenciou a partir de 2016, quando o próprio Estado decidiu reverter a ampliação de direitos constitucionais, com a aprovação da Emenda Constitucional n. 95 (BRASIL, 2016). Tal aprovação rompeu o ciclo imediatamente anterior e, certamente, quebrou o pacto fiador promovido pela Constituição da República Federativa do Brasil (1988). Novas interseções entre União e entes federativos já se encontram em curso, para atender aos imperativos da austeridade fiscal. 


\section{REFERÊNCIAS}

AMARAL, N. C. Com a PEC 241/55 (EC95) haverá prioridade para cumprir as metas do PNE (2014-2024)? Revista Brasileira de Educação, Rio de Janeiro, v. 22, n. 71, p. 1-25, 2017.

ARELARO, L. R. G.; FERNANDES, M. D. E. O Fundeb no contexto das relações federativas brasileiras: implicações para a valorização docente. In: GOUVEIA, A. B.; PINTO, J. M. de R.; FERNANDES, M. D. E. Financiamento da Educação no Brasil: os desafios de gastar 10\% do PIB em dez anos. Campo Grande: Oeste, 2015. p. 177-198.

ARELARO, L. R. G. Financiamento e qualidade da educação brasileira. Algumas reflexões sobre o "Documento Balanço do Primeiro ano do Fundef - Relatório MEC". In: DOURADO, L. F. (org.). Financiamento da educação básica: polêmicas do nosso tempo. Campinas, SP: Autores Associados; Goiânia, GO: UFG, 1999.

BARBOSA, N. Dez anos de política econômica. In: SADER, Emir (org.). 10 anos de governos pós-neoliberais: Lula e Dilma. São Paulo: Boitempo; Rio de Janeiro: Flacso Brasil, 2013. p. 69-102.

BASTOS, P. P. Z. Ascenção e crise do governo Dilma Rousseff e o golpe de 2016: poder estrutural, contradição e ideologia. Revista de Economia Contemporânea, Rio de Janeiro, v. 21, n. 2, p. 1-63, dez. 2017.

BRASIL. Constituição da República Federativa do Brasil de 1988. Senado Federal, Brasília, 1988.

BRASIL. Decreto n. 6.253, de 13 de novembro de 2007. Dispõe sobre o FUNDEB [...]. Brasília, 2007a. Disponível em: http://www.planalto.gov.br/ ccivil_03/_Ato2007-2010/2007/Decreto/D6253.htm. Acesso em: 6 abr. 2020.

BRASIL. Emenda Constitucional n. 108, de 26 de agosto de 2020. Altera a Constituição Federal para [...] dispor sobre o Fundo de Manutenção e Desenvolvimento da Educação Básica e de Valorização dos Profissionais da Educação (Fundeb) [...]. Diário Oficial da União, Brasília, 27 ago. 2020, n. 165, Seção 1, p. 5. 
BRASIL. Emenda Constitucional n. 53, de 19 de dezembro de 2006. Dá nova redação aos arts. $7^{\circ}, 23,30,206,208,211$ e 212 da Constituição Federal e ao art. 60 do Ato das Disposições Constitucionais Transitórias. Brasilia, 2006. Disponível em: http://www.planalto.gov.br/ccivil_03/constituicao/Emendas/Emc/emc53. htm. Acesso em: 20 mar. 2020.

BRASIL. Emenda Constitucional n. 95, de 16 de dezembro de 2016. Altera o Ato das Disposições Constitucionais Transitórias, para instituir o Novo Regime Fiscal [...] Diário Oficial da União, Brasília, 16 dez. 2016, n. 241, Seção 1, p. 2-3.

BRASIL. Lei n. 11.494, de 20 de junho de 2007. Regulamenta o Fundo de Manutenção e Desenvolvimento da Educação Básica e de Valorização dos Profissionais da Educação [...]. Brasília, 2007b. Disponível em: http://www. planalto.gov.br/ccivil_03/_ato2007-2010/2007/lei/111494.htm. Acesso em: 20 mar. 2020.

BRASIL. Lei n. 11.738, de 16 de julho de 2008. Regulamenta a alínea "e" do inciso III do caput do art. 60 do Ato das Disposições Constitucionais Transitórias, para instituir o piso salarial profissional nacional [...]. Brasília, 2008. Disponível em: http://www.planalto.gov.br/ccivil_03/_ato2007-2010/2008/lei/111738.htm. Acesso em: 8 maio 2020.

BRASIL. Lei n. 13.005, de 25 de junho de 2014. Aprova o Plano Nacional de Educação [...]. Disponível em: http://www.planalto.gov.br/ccivil_03/_ato20112014/2014/lei/113005.htm.

Acesso em: 20 mar. 2020.

BRASIL. Ministério da Fazenda. Anexo de metas fiscais e relatório resumido da execução orçamentária: manual de elaboração - aplicado à União e aos Estados, Distrito Federal e Municípios. 7. ed. atual. Brasilia: Secretaria do Tesouro Nacional, Coordenação-Geral de Contabilidade, 2007. Disponível em: http:// www.sepog.ro.gov.br/Uploads / Arquivos / PDF/LDO/2016/PROJETO/ Manual\%20LDO \%202016.pdf. Acesso em: 16 abr. 2016.

CONFEDERAÇÃO NACIONAL DOS TRABALHADORES EM EDUCAÇÃO. Cassol nega reajuste salarial e diz que a culpa é da crise mundial. 30 mar. 2009. Disponível em: http://www.cnte.org.br/index.php/ cnte-informa/1201-cnte-informa-475-30-demarco-de-2009/1760-giro-pelosestados.html. Acesso em: 21 abr. 2018. 
CONFEDERAÇÃO NACIONAL DOS TRABALHADORES EM EDUCAÇÃO. Greve atingiu todo o estado. 18 mar. 2008a. Disponível em: http://www.cnte.org.br/ index.php/cnte-informa/1150-cnte-informa-424-18de-marco-de-2008/534-giro-pelosestados.html. Acesso em: 21 abr. 2018.

CONFEDERAÇÃO NACIONAL DOS TRABALHADORES EM EDUCAÇÃO. Sindicato de Rondônia cobra enquadramento imediato dos profissionais da educação no plano de carreira. 01 set. 2008b. Disponível em: http:/ /www.cnte.org.br/index.php/cnteinforma/1174-cnte-informa-448-01-desetembro-de-2008/1109-giro-pelos-estados.html. Acesso em: 21 abr. 2018.

CONFEDERAÇÃO NACIONAL DOS TRABALHADORES EM EDUCAÇÃO. Sindicatos de servidores unidos para reivindicar reajuste salarial. 8 dez. 2008c. Disponível em: http://www.cnte.org.br/index.php/cnteinforma/1187-cnte-informa-461-09-dedezembro-de-2008/1419-giro-pelosestados.html. Acesso em: 21 abr. 2018.

CURY, C. R. J. A qualidade da educação brasileira como direito. Educação \& Sociedade, Campinas, v. 35, n. 129, p. 1053-1066, dez. 2014.

DOURADO, L. F. Plano Nacional de Educação: o epicentro das políticas de Estado para a educação brasileira. Goiânia: Editora da Imprensa Universitária/ ANPAE, 2017.

DWECK, E.; TEIXEIRA, R. A. A política fiscal do governo Dilma e a crise econômica. Texto para discussão, Campinas, n. 303, p. 1-41, jun. 2017. Disponível em: www.eco.unicamp.br/docprod/downarq.php?id=3532\&tp=a. Acesso em: 15 jan. 2018.

FÁVERO, L. P. L. et al. Análise da dados: modelagem multivariada para tomada de decisões. Rio de Janeiro: Elsevier, 2009.

FERNANDES, M. D. E.; FERNANDES, S. J. Vencimento salarial de professores na esfera municipal em tempos de fundos contábeis. Fineduca: Revista de Financiamento da Educação, Porto Alegre, v. 4, p. 1-22, 2014. Disponível em: https://seer.ufrgs.br/fineduca/article/view/66312. Acesso em: 26 nov. 2017. 
FERNANDES, M. D. E.; FERNANDES, S. J. Vencimento salarial docente: o caso do FUNDEB e do PSPN. Retratos da Escola, Brasília, v. 10, n. 18, p. 275-292, jan./jun. 2016. DOI: http://dx.doi.org/10.22420/rde.v10i18.664. Disponível em: http://www.esforce.org.br/index.php/semestral/article/view/664/686. Acesso em: 12 jan. 2017.

FERNANDES, M. D. E.; RODRIGUEZ, M. V. O processo de elaboração da Lei n. 11.738/2008 (Lei do Piso Salarial Profissional Nacional para carreira e remuneração docente): trajetória, disputas e tensões. Revista HISTEDBR Online, Campinas, n. 41, p. 88-101, mar. 2011. Disponível em: https://periodicos. sbu.unicamp.br/ojs/index.php/histedbr/article/view/8639837/7400. Acesso em: 15 mar. 2016.

FERNANDES, M. D. E.; MIURA, B. H. Remuneração docente: efeitos da luta sindical na implantação do piso salarial nacional professional. Revista Educação e Emancipação, São Luís, v. 12, n. 3, set./dez. p. 114-137, 2019. DOI: http:// dx.doi.org/10.18764/2358-4319.v12n3p114-137. Disponível em: http://www. periodicoseletronicos.ufma.br/index.php/reducacaoemancipacao/article/ view/12404. Acesso em: 10 ago. 2020.

GOUVEIA, A. B.; BASSI, M. E. Vencimento dos professores no contexto das finanças públicas do Paraná e de Santa Catarina, Brasil. Revista Educação em Questão, Natal, v. 54, p. 101-128, 2016. DOI: https://doi.org/10.21680/19811802.2016v54n40ID9850. Disponível em: https://periodicos.ufrn.br/ educacaoemquestao/article/viewFile/9850/6978. Acesso em: 26 nov. 2017.

GOUVEIA, A. B.; FERRAZ, M. A. dos S. Financiamento da educação e luta sindical: conflitos em uma grande rede de ensino. Educação \& Sociedade, Campinas, v. 37, p. 285-302, 2016.

GOUVEIA, A. B.; SOUZA, Â. R. de. A política de fundos em perspectiva histórica: mudanças de concepção da política na transição Fundef e Fundeb. Em Aberto, Brasilia, v. 28, n. 93, p. 45-65, 2015.

INSTITUTO BRASILEIRO DE GEOGRAFIA E ESTATÍSTICA. Índice Nacional de Preço ao Consumidor Amplo - IPCA. Séries históricas, 2019. Disponível em: https://www.ibge.gov.br/estatisticas-novoportal/economicas/ precos-e-custos /9256-indice-nacional-de-precos-ao-consumidor-amplo. html? =\&t=series-historicas. Acesso em: 24 mar. 2020. 
LABORATÓRIO DE DADOS EDUCACIONAIS. Plataforma de dados educacionais. Curitiba: UFPR; Goiânia: UFG, 2020. Disponível em: https:// dadoseducacionais.c3sl.ufpr.br/\#/consultas. Acesso em: 15 ago. 2020.

MARCONI, N.; BRANCHER, M. A política econômica do novo desenvolvimentismo. Revista de Economia Contemporânea, Rio de Janeiro, v. 21, n. 2, p. 1-31, dez. 2017. DOI:

MELLO, G.; ROSSI, P. Do industrialismo à austeridade: a política macro dos governos Dilma. Texto para discussão, Campinas, n. 309, p. 1-36, jun. 2017. Disponível em: www.eco.unicamp.br/docprod/downarq.php?id=3538\&tp=a. Acesso em: 15 jan. 2018.

NASCIMENTO, A. B. N. Financiamento da educação e política de valorização docente no Brasil. In: NASCIMENTO, Alessandra Bertasi. (Des)feitos e (d) efeitos na composição remuneratória de docentes da rede estadual de educação básica de Rondônia no contexto das políticas do Fundeb e PSPN [2006 a 2016]. 2019. Tese (Doutorado em Educação) - Universidade Federalde Mato Grosso do Sul, Campo Grande, 2019. p. 87-117. Disponível em: http:// posgraduacao.ufms.br/portal/trabalho-arquivos/download/6405. Acesso em 4 set. 2019.

OLIVEIRA, M. dos S. de; FERNANDES, M. D. E. A Constituição Federal de 1988 face às emendas constitucionais correlatas à educação. Revista Educação e Políticas em Debate, v. 7, n. 2, p. 313-327, maio/ago. 2018. DOI: https://doi. org/10.14393/REPOD.issn.2238-8346.v7n2a2018-08. Disponível em: http:// www.seer.ufu.br/index.php/revistaeducaopoliticas/article/view/47063. Acesso em: 10 jul. 2019.

PINTO, J. M. de R. A política recente de fundos para o financiamento da educação e seus efeitos no pacto federativo. Educação \& Sociedade, Campinas, v. 28, n. 100 esp., p. 877-897, out. 2007.

RONDÔNIA. Decreto n. 20.070, de 24 de agosto de 2015. Institui Programa de Parceira Educacional Estado-Município para universalizar o atendimento do Ensino Fundamental. Diário Oficial do Estado, Porto Velho, RO, 24 ago. 2015a, n. 2767, Caderno Principal, p. 11-14. 
RONDÔNIA. Lei Complementar n. 420, de 09 de janeiro de 2008. Dispõe sobre o Plano de Carreira, Cargos e Remuneração dos Profissionais da Educação Básica do Estado de Rondônia, e dá outras providências. In: ASSEMBLEIA LEGISLATIVA DO ESTADO DE RONDÔNIA. Sistema de apoio ao processo legislativo. Porto Velho: Assembleia Legislativa do Estado de Rondônia, 2008a. Disponível em: http://sapl.al.ro.leg.br/sapl_documentos/ norma_juridica/3849_texto_integral. Acesso em: 14 mar. 2017.

RONDÔNIA. Lei Complementar n. 499, de 10 de março de 2009. Cria, no âmbito da [...] SEDUC, o Complemento Salarial para o Piso Salarial Nacional do Magistério. In: ASSEMBLEIA LEGISLATIVA DO ESTADO DE RONDÔNIA. Sistema de apoio ao processo legislativo. Porto Velho: Assembleia Legislativa do Estado de Rondônia, 2009a. Disponível em: https://sapl.al.ro.leg.br/media/ sapl/public/normajuridica/2009/4374/4374_texto_integral.pdf. Acesso em: 12 mar. 2017.

RONDÔNIA. Lei Complementar n. 680, de 07 de setembro de 2012. Dispõe sobre o Plano de Carreira, Cargos e Remuneração dos Profissionais da Educação Básica do Estado de Rondônia e dá outras providências. Diário Oficial do Estado, Porto Velho, RO, 07 set. 2012b, n. 2.054, Caderno Especial, p. 2-12.

RONDÔNIA. Lei n. 3.565, de 03 de junho de 2015b. Institui o Plano Estadual de Educação. Diário Oficial do Estado, Porto Velho, RO, 3 jun. 2015c, n. 2.712, Caderno Principal, p. 3. Disponível em: http://www.diof.ro.gov.br/data/ uploads/2015/06/Doe-_-03-06-2015.pdf. Acesso em: 24 out. 2017

RONDÔNIA. Relatório resumido da execução orçamentária: anexo X - jan./ dez. 2007. Diário Oficial do Estado, Porto Velho, RO, 30 de janeiro de 2008b, n. 0926, Caderno Principal, p. 8-9.

RONDÔNIA. Relatório resumido da execução orçamentária: anexo X - jan./ dez. 2008. Diário Oficial do Estado, Porto Velho, RO, 30 de janeiro de 2009, n. 1174, Caderno Principal, p. 13-15.

RONDÔNIA. Relatório resumido da execução orçamentária: anexo X - jan./ dez. 2009. Diário Oficial do Estado, Porto Velho, RO, 26 de fevereiro de 2010, n. 1437, Caderno Principal, p. 17-18. 
RONDÔNIA. Relatório resumido da execução orçamentária: anexo X - jan./ dez. 2010. Diário Oficial do Estado, Porto Velho, RO, 28 de janeiro de 2011, n. 1663, Caderno Principal, p. 48-50.

RONDÔNIA. Relatório resumido da execução orçamentária: anexo X - jan./ dez. 2011. Diário Oficial do Estado, Porto Velho, RO, 30 de janeiro de 2012, n. 1906, Caderno Principal, p. 27-29.

RONDÔNIA. Relatório resumido da execução orçamentária: anexo X - jan./ dez. 2012. Diário Oficial do Estado, Porto Velho, RO, 29 de janeiro de 2013, n. 2145, Caderno Principal, p. 37-39.

RONDÔNIA. Relatório resumido da execução orçamentária: anexo 8 - jan./ dez. 2013. Diário Oficial do Estado, Porto Velho, RO, 29 de janeiro de 2014, n. 2389, p. 67-71.

RONDÔNIA. Relatório resumido da execução orçamentária: anexo 8 - janeiro a dezembro de 2014. Diário Oficial do Estado, Porto Velho, RO, 30 de janeiro de 2015c, n. 2632, Caderno Principal, p. 39-42.

RONDÔNIA. Relatório resumido da execução orçamentária: anexo 8 - janeiro a dezembro de 2015. Diário Oficial do Estado, Porto Velho, RO, 26 de fevereiro de 2016, n. 36, Caderno Principal, p. 70-71.

RONDÔNIA. Relatório resumido da execução orçamentária: anexo 8 - jan./dez. 2016. Diário Oficial do Estado, Porto Velho, RO, 30 de janeiro de 2017, n. 19, Caderno Principal, p. 117-119.

RONDÔNIA. Relatório resumido da execução orçamentária: anexo 8 - jan./dez. 2017. Diário Oficial do Estado, Porto Velho, RO, 30 de janeiro de 2018, n. 19, p. 68-74.

RONDÔNIA. Relatório resumido da execução orçamentária: anexo 8 - jan./dez. 2018. Diário Oficial do Estado, Porto Velho, RO, 30 de janeiro de 2019, n. 19, p. 230-236.

RONDÔNIA. Relatório resumido da execução orçamentária: anexo 8 - jan./dez. 2019. Diário Oficial do Estado, Porto Velho, RO, 30 de janeiro de 2020, n. 20, p. 73-78. 
RONDONOTÍCIAS. PIB de Rondônia registra crescimento de 5,4\%, afirma IBGE, 13 dez. 2019. Disponível em: http://rondonoticias.com.br/ noticia/geral/33087/ pib-de-rondonia-registra-crescimento-de-5-4-afirma-ibge. Acesso em: 25 fev. 2020.

ROSSI, P. et al. Austeridade fiscal e o financiamento da educação no Brasil. Educação \& Sociedade, Campinas, v. 40, e0223456, p. 1-20, 2019.

\section{Alessandra Bertasi Nascimento}

Doutora em Educação pela Universidade Federal de Mato Grosso do Sul (UFMS), Professora adjunta do curso de História, Nova Andradina/UFMS.

Email: alessandra.bertasi@ufms.br

\section{Maria Dilnéia Espíndola Fernandes}

Doutora em Educação pela Universidade Estadual de Campinas (Unicamp). Professora Titular da Universidade Federal do Mato Grosso do Sul, onde atua como pesquisadora sênior no Programa de Pós-graduação em Educação. Bolsista em Produtividade CNPq (Nível 1D).E-mail: mdilneia@uol.com.br

\section{Leandro Sauer}

Doutor em Engenharia Elétrica (UNICAMP), Professor Associado da Escola de Administração e Negócios/UFMS e do Programa de Pós-Graduação em Administração. E-mail: leandrosauer@uol.com.br 